\title{
Tinea incognito with unjustified use of potent Topical Corticosteroids: a case series
}

\author{
Haiya J. Sheth ${ }^{1}$, Santosh P. Rathod ${ }^{2}$, Raju G. Chaudhary ${ }^{2}$, \\ Supriya D. Malhotra ${ }^{1 *}$, Pankaj R. Patel ${ }^{3}$
}

${ }^{1}$ Department of Pharmacology, ${ }^{2}$ Department of Dermatology, ${ }^{3}$ Department of Orthopedics, Smt. NHLMMC, Ahmedabad, Gujarat, India

Received: 30 May 2017 Accepted: 24 June 2017

\section{*Correspondence to: Dr. Supriya D. Malhotra, Email: supriyadmalhotra@ gmail.com}

Copyright: () the author(s), publisher and licensee Medip Academy. This is an openaccess article distributed under the terms of the Creative Commons Attribution NonCommercial License, which permits unrestricted noncommercial use, distribution, and reproduction in any medium, provided the original work is properly cited.

\begin{abstract}
Topical corticosteroids prescribed for various dermatological conditions, if used haphazardly have their adverse effects too, like aggravation of underlying infections - tinea, herpes etc. Tinea incognito is a fungal infection of skin masked and often exacerbated by application of topical immunosuppressive or steroid agent. Tinea incognito results because local physicians/chemists might mistake tinea with a simple rash. Availability of a topical steroid cream as an over the counter (OTC) drug is also one of the causes. Once it is diagnosed (clinically with or without $\mathrm{KOH}$ mount preparation), it should be thoroughly treated with oral and topical antifungal agents. Four cases presenting to Dermatology OPD VSGH with chief complaints of itching and aggravation of existing lesions due to application of potent topical corticosteroids like Clobetasol and Beclomethasone have been discussed here. They were diagnosed as cases of Topical Corticosteroids induced Tinea Incognito. The patients were recovering with oral and topical antifungals prescribed by dermatologist. These were also reported to nearest ADR Monitoring Centre under PvPI with Probable causality according to WHO UMC Criteria for Causality Assessment. The wide use of topical corticosteroids is due to its immediate symptomatic relief. However, the normal presentation of superficial infection gets altered with their inappropriate use. Lack of awareness among population, steroid abuse by local physicians or no strict regulations for local chemist shops have led to its inappropriate use. Its incidence ranges from 5 $15 \%$. These figures point towards the fact that implementation of appropriate regulations for the safe use of topical corticosteroids is essential.
\end{abstract}

Keywords: Betamethasone, Clobetasol, Dermatology, Misuse, Tinea Incognito

\section{INTRODUCTION}

The use of corticosteroids for various dermatological conditions is widely known. Topical steroids are the most commonly prescribed drugs in dermatology outdoor patient department for the treatment of eczema, dermatitis, rash, autoimmune conditions, etc. ${ }^{1}$ However, their haphazard use may result into various adverse effects. The most frequent adverse effects include atrophy, striae, rosacea, perioral dermatitis, acne, and purpura etc. ${ }^{2}$ Topical steroids can aggravate or mask skin infections e.g. impetigo, tinea, herpes etc. ${ }^{3}$
Tinea Incognito is a cutaneous fungal infection. It is the name given to tinea when the clinical appearance has been altered by inappropriate treatment, usually a topically steroid cream. ${ }^{4}$ In other words, Tinea incognito is a fungal infection of skin masked and often exacerbated by application of topical steroid or immunosuppressive agent. As the skin fungal infection has lost some of the characteristic features due to suppression of inflammation, it may have a poorly defined border and florid growth. ${ }^{5}$

In a case of Tinea Incognito, history of topical steroid application is because of the fact that tinea infection may 
sometimes be mistaken as a simple rash by local physicians/chemists. Availability of topical steroid preparations as an OTC (over the counter) drug is also one of the causes for steroid abuse.

Topical steroids are also available in combination with antifungal agents. Abuse with these fixed dose combinations (FDCs) is also endless since they are bought over the counter and applied for endless number of days. The immunosuppression by the topical steroid is significant enough to cause tinea incognito to occur even in the presence of an effective antifungal. ${ }^{5}$ Once Tinea Incognito is diagnosed (clinically with or without $\mathrm{KOH}$ mount preparation), it should be thoroughly treated with oral and topical antifungal agents as directed by the treating dermatologist.

Four cases presenting to Dermatology OPD VSGH in February 2017 are included in this case series.

\section{CLINICAL CASE STUDY}

\section{Case 1}

Report id $=2017-05686$

A 37 years old female presented with chief complaints of erythematous lesion over the abdomen associated with itching since 2 months (Figure 1). The lesion had aggravated since 1 month following the application of Clobetasol $0.05 \%$ ointment for 1 month. The treating dermatologist diagnosed it as Clobetasol induced Tinea Incognito.

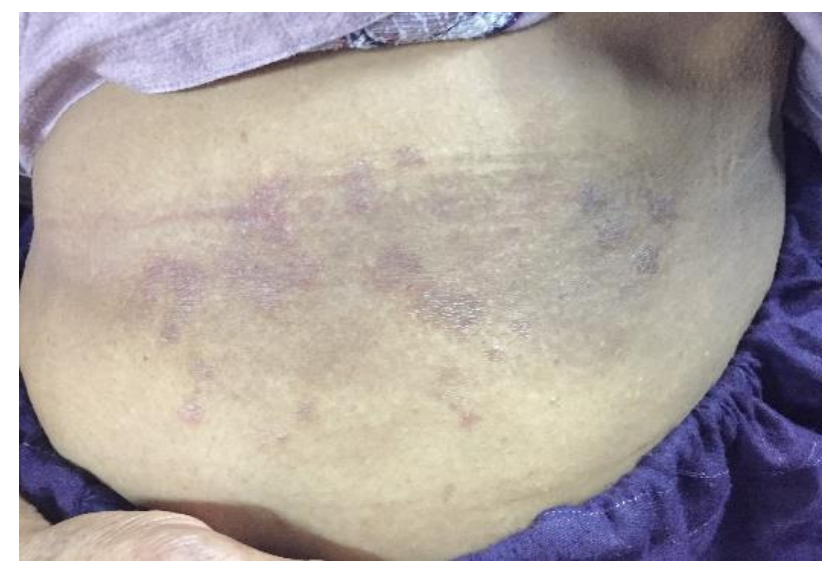

Figure 1: Lesion over the abdomen.

\section{Case 2}

Report id $=2017-05689$

A 42 years old male presented with chief complaints of skin lesion over the back, forearms and forehead associated with severe itching since 1 month (Figure 2). It had aggravated since 1 week after applying Clobetasol
$0.05 \%$ ointment for 1 month. The treating dermatologist diagnosed it as Clobetasol induced Tinea Incognito.

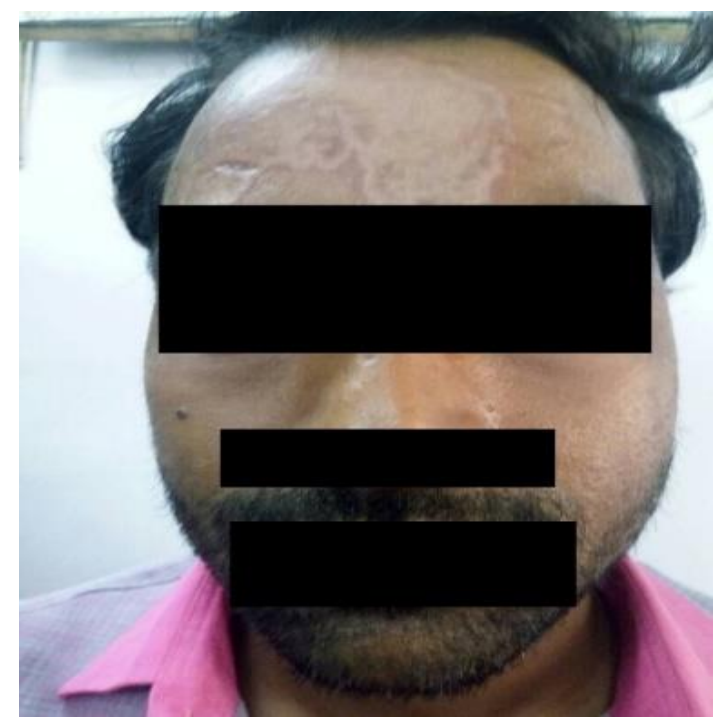

Figure 2: Lesion over the forehead.

Case 3

Report id = 2017-05845

A 24 years old female presented with chief complaints of severe itching over the erythematous lesion on her thighs bilaterally since 5-6 months (Figure 3). It had aggravated following the application of Beclomethasone $0.025 \%$ cream for 5 months. The treating dermatologist diagnosed it as Beclomethasone induced Tinea Incognito.

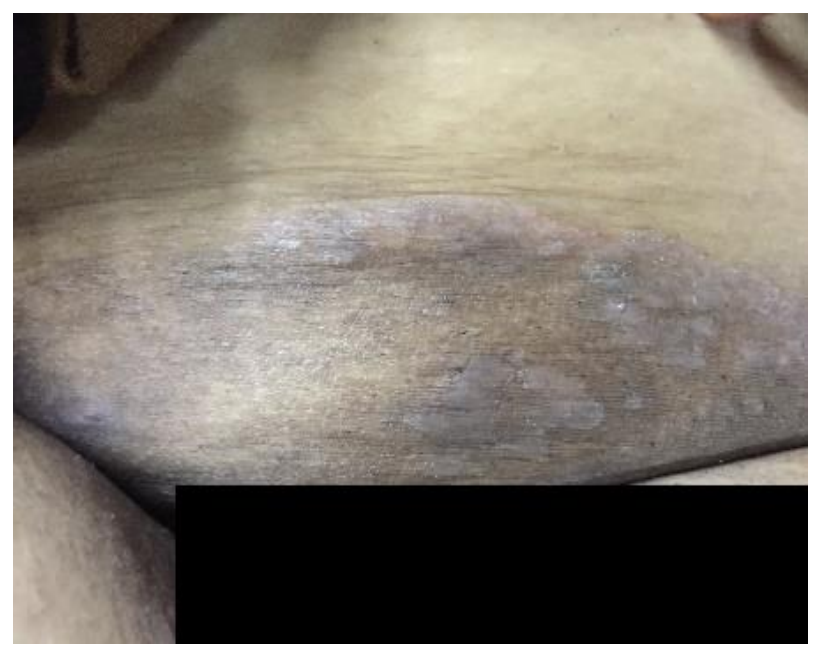

Figure 3: Lesion over the medial aspect of right thigh.

\section{Case 4}

Report id $=2017-05689$

A 56 years old female presented with chief complaints of erythematous lesion over her neck associated with severe 
itching since 5-6 months (Figure 4). The lesion had aggravated since 2-3 months following the application of Beclomethasone $0.025 \%$ cream for over 3 months. The treating dermatologist diagnosed it as Beclomethasone induced Tinea Incognito.

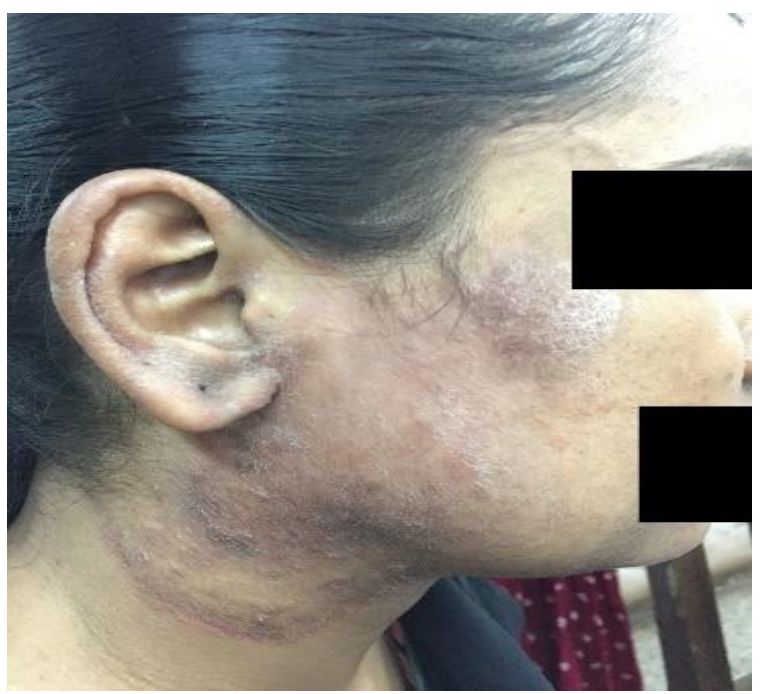

Figure 4: Lesion over the neck.

These patients had been prescribed potent topical steroids either by a local physician or got it as an OTC drug from a local chemist. They were asked to stop the application of respective topical steroid immediately by the treating dermatologist. They also started recovering following the oral and topical antifungal treatment prescribed by the dermatologist.

These cases were also reported to the nearest ADR Monitoring Centre under Pharmacovigilance Programme of India. The causality in all four cases was termed as Probable according to the WHO UMC Criteria for Causality Assessment.

\section{DISCUSSION}

The wide use of topical corticosteroids is due to its immediate symptomatic relief. Even in infections though not to be used ideally, the symptoms improve temporarily owing to its anti-inflammatory and immunosuppressive actions. This may result in prolonged use/misuse of topical corticosteroid which leads to worsening of existing infections such as tinea and other adverse effects as mentioned above.

Also, the normal presentation of superficial infections can be altered when topical corticosteroids are inappropriately used to treat fungal infections. ${ }^{6}$ The reason being lack of awareness among the population, steroid abuse by local physicians, incorrect diagnosis as well as no strict regulations for local chemist shops whether to sell a drug without a prescription or not. Direct to consumer advertising of these creams is also a culprit in increased incidences of tinea incognito.
The formulations of Topical Steroids with antifungal agents account for about $50 \%$ of the sales. ${ }^{7}$ The commonly available FDC of an antifungal agent bought over the counter is Clobetasol propionate. People often stop using them when the itching and redness are mitigated and begin to apply again when the symptoms reappear. ${ }^{7}$ This ineffective elimination of the dermatophyte is due to an inappropriate treatment of superficial dermatophyte infection, thereby resulting in chronic and widespread lesion.

The incidence of misuse of topical corticosteroid ranges from 5\%-15\%. A study done by Saraswat A et al at a rural tertiary care teaching hospital in Maharashtra, India concluded that $28 \%$ of 500 prescriptions had topical steroids, out of which $98 \%$ were very potent corticosteroids (Beclomethasone, Clobetasol); and in $85 \%$ of cases, the basis of prescribing topical steroids could not be established. ${ }^{8}$

Few authors have used the terms "Tinea pseudoimbricata" for Tinea Incognito because it is reminiscent of tinea imbricata characterized by multiple concentric rings and has been explained to be occurring due to partial immune response. ${ }^{7}$ However, more appropriate term is "steroid modified tinea". 7,9

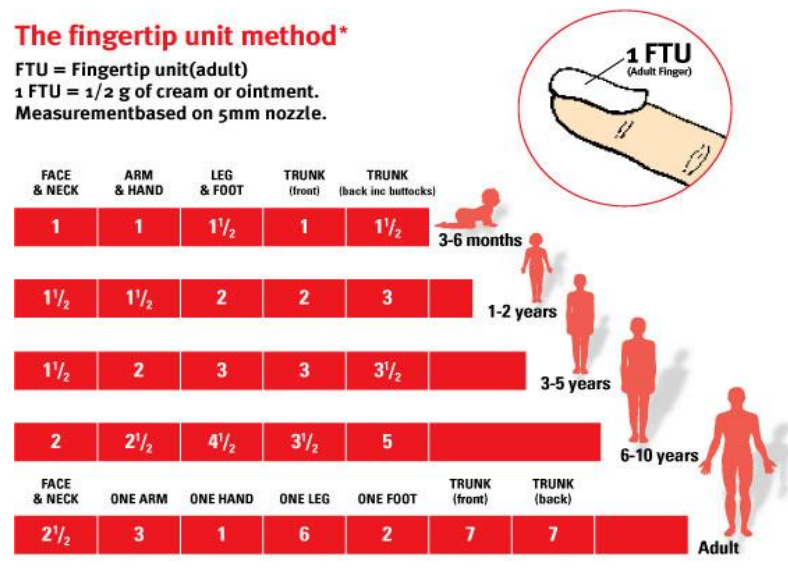

Figure 5: Finger tip unit method.

All these data point towards the fact that strict regulations need to be implemented for the safe use of topical corticosteroids. In August 2016, the Drug Controller General of India (DCGI) as per the recommendations of Indian Association of Dermatologists, Venerologists, Leprologists (IADVL) has included most major topical steroid molecules as Schedule $\mathrm{H}$ drugs meaning legally they cannot be sold over the counter and without a valid prescription of a medical practitioner; however the Gazette notification to this effect issued in the third quarter of 2016 has still not been implemented and all topical steroids continue to be sold freely in the market. ${ }^{7}$ Pharmaceutical companies should be made to ensure proper labelling of topical steroid products which should include inserts containing clear "fingertip unit" instruction (see Figure 5), preferably with images and charts to show the numbers of 
units required for specific areas of the body. ${ }^{10}$ The irrational FDCs (combination of topical antifungal, antibacterial, steroid) and various others available in the market freely should be banned by the DCGI and state licensing authorities.

Topical corticosteroids should not be chosen as $1^{\text {st }}$ line treatment unless the diagnosis is confirmed. In order to prevent the incidence of adverse effects, use of mildly potent topical steroids should be encouraged over very potent ones wherever necessary.

\section{ACKNOWLEDGEMENTS}

Authors would like to thank the professors and residents in the Dermatology Department for their help and guidance.

Funding: No funding sources

Conflict of interest: None declared

Ethical approval: Not required

\section{REFERENCES}

1. Wikipedia contributors, Wikipedia: The Free Encyclopedia. Topical steroid, December 15, 2016. Available https://en.wikipedia.org/w/index.php?title=Topical_st eroid\&oldid=754953529. Accessed May 42017.

2. Hengge U, Ruzicka T, Schwartz R, Cork M. Adverse effects of topical glucocorticosteroids. By American Academy of Dermatology, Inc.; January 2006.

3. DermNet, New Zealand: All About Skin. Topical Steroids, $1997 . \quad$ Available at: http://www.dermnetnz.org/topics/topical steroids/. Accessed May 42017.
4. DermNet New Zealand: All About Skin. Tinea Incognito, 2003. Available at: http://www.dermnetnz.org/topics/tinea-incognito/. Accessed May 42017.

5. Wikipedia contributors, Wikipedia: The Free Encyclopedia. Tinea Incognito, December 14, 2015. Available at: https://en.wikipedia.org/w/index.php?title=Tinea_inc ognito\&oldid=695142577. Accessed May 42017.

6. Kumar S, Goyal A, Gupta YK. Abuse of topical corticosteroids in India: Concerns and the way forward. J Pharmacol Pharmacother. 2016;7:1-5.

7. Verma S, Madhu R. The great Indian Epidemic of superficial dermatophytosis: An appraisal. Indian $\mathbf{J}$ Dermatol. 2017;62:227-36.

8. Saraswat A, Lahiri K, Chatterjee M, Barua S, Coondoo A, Mittal A, et al. Topical corticosteroid abuse on the face: A prospective, multicenter study of dermatology outpatients. Indian J Dermatol Venereol Leprol. 2011;77:160-6.

9. Panda S, Verma S. The menace of dermatophytosis in India: The evidence that we need. Indian J Dermatol Venereol Leprol. 2017;83:281-4.

10. Rathi SK, D'Souza P. Rational and Ethical Use of Topical Corticosteroids Based on Safety and Efficacy. Indian Journal of Dermatology. 2012;57(4):251-9.

Cite this article as: Sheth HJ, Rathod SP, Chaudhary RG, Malhotra SD, Patel PR. Tinea incognito with unjustified use of potent Topical Corticosteroids: a case series. Int J Basic Clin Pharmacol 2017;6:2087-90. 